\title{
Determination of Single Knife Edge Equivalent Parameters for Triple Knife Edge Diffraction Loss by Giovanelli Method
}

\author{
Ezenugu Isaac A., Ikechukwu H. Ezeh, Swinton C. Nwokonko \\ Department of Electrical/Electronic Engineering, Imo State University, Owerri, Nigeria
}

Email address:

isaac.ezenugu@yahoo.com (Ezenugu I. A.)

\section{To cite this article:}

Ezenugu Isaac A., Ikechukwu H. Ezeh, Swinton C. Nwokonko. Determination of Single Knife Edge Equivalent Parameters for Triple Knife Edge Diffraction Loss by Giovanelli Method. International Journal of Information and Communication Sciences.

Vol. 2, No. 1, 2017, pp. 10-14. doi: 10.11648/j.ijics.20170201.12

Received: January 1, 2017; Accepted: February 9, 2017; Published: April 22, 2017

\begin{abstract}
In this paper, the computation of triple knife edge diffraction loss by Giovanelli multiple knife edge diffraction loss method is presented for a $10 \mathrm{GHz} \mathrm{Ku}$-band microwave link. Also, the computation of equivalent single knife edge obstruction that will replace the triple obstruction by giving the same diffraction loss as the dual obstructions is presented. The results shows that for the triple obstructions (M1, M2 and M3) the total diffraction loss is $59.5095778 \mathrm{~dB}$ as computed by the Giovanelli method. The individual diffraction loss from obstructions M1, M2 and M3 are $13.3856983 \mathrm{~dB}, 29.59291 \mathrm{~dB}$ and $16.5309693 \mathrm{~dB}$ respectively. Furthermore, a single knife edge obstruction located at the middle of the link $(\mathrm{dt}=\mathrm{dr}=4475 \mathrm{~m})$ and with LOS clearance height of $1237.591 \mathrm{~m}$ will be give the same diffraction loss as the three knife edge obstructions M1, M2 and M3. Essentially, the line of sight clearance height of the equivalent single knife edge obstruction are much more than the sum of the line of sight clearance height of the three original obstructions.
\end{abstract}

Keywords: Diffraction Parameter, Diffraction Loss, Knife Edge obstruction, Multiple Knife Edge Obstruction, Equivalent Single Knife Edge Obstruction, Giovanelli Method

\section{Introduction}

In wireless communication systems, pathloss is one of the major components used in link budgeting to determine the expected received signal strength [1-6]. Basically, pathloss is the reduction in power density of an electromagnetic wave as it propagates through space [7-10]. Pathloss can be caused by many effects, such as free-space loss, refraction, diffraction, reflection, aperture-medium coupling loss, and absorption. Diffraction loss occurs when the line of sight (LOS) is blocked by an obstruction. In that case, the signal bends around the obstacle [11-17].

The concept of diffraction is explained by the Huygens-Fresnel principle [18-20]. The common practice is that isolated obstruction like hill or building are considered as knife edge obstruction [21-23]. When there are two or more of such knife edge obstructions, then multiple knife edge diffraction loss methods can be employed to determine the effective diffraction loss of all the knife edge obstructions [24]. Several multiple knigfe edge diffraction methods hase bee developed such as Bullington, Epstein and Peterson, Deygout,
Shibuya and Giovaneli methods. The listed are approximation method for determination of the effective diffraction loss that can be caused by a given set of multiple knife edge obstructions in the signal path. knife edge diffraction using he Giovaneli method is presented for a $10 \mathrm{GHz} \mathrm{Ku}$-band microwaave link. Furthermore, the computation of a single knife edge equivalent of the triple knife edge is presented.

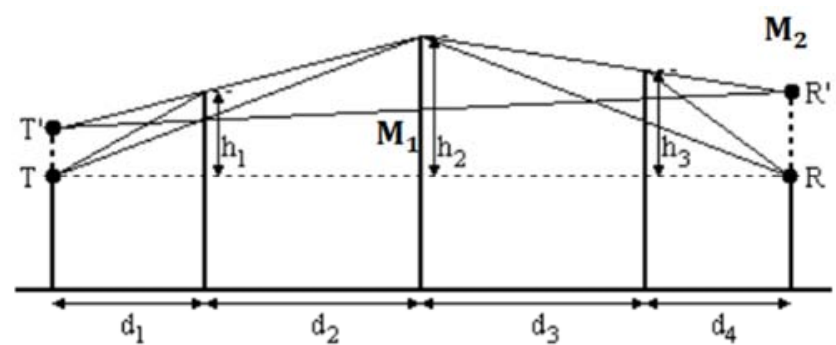

Figure 1. The Geometry for the Giovanelli method [25]. 


\section{Giovanelli Multiple Knife Edge Diffraction Loss Method}

Let $\lambda$ be the wavelength of the radio wave; let $\mathrm{c}$ be the speed of the radio wave (where $\mathrm{c}=3 \times 10^{8} \mathrm{~m} / \mathrm{s}$ and let $\mathrm{f}$ be the frequency of the radio wave in $\mathrm{Hz}$, then, the radius of the first Fresnel zone at location $\mathrm{x}$ is denoted as $\mathrm{r}_{x}$ which is at a distance of $d_{t(x)}$ from the transmitter and at a distance of $d_{r(x)}$ from the receiver, then;

$$
r_{x}=\sqrt{\frac{\kappa\left(d_{t(x)}\right)\left(d_{r(x)}\right)}{\left(d_{t(x)}+d_{r(x)}\right)}}
$$

$\lambda$ in metres is given as;

$$
\Lambda=\frac{c}{f}
$$

Based on the three knife edge obstructions $\left(\mathrm{M}_{1}, \mathrm{M}_{2}\right.$ and $\mathrm{M}_{3}$ ) in Figure 1 the following procedure is used in Giovaneli method to determine the effective diffraction loss due to the three knife edge obstructions. In Giovaneli method, first, the dominant obstruction is determined from $\left(\mathrm{q}_{i}\right)$ the ratio of the obstruction i LOS clearance height $\left(h_{i}\right)$ and $r_{i}$ which is the radius of the first Fresnel zone at obstruction's location. From figure 1 , for the knife edge obstruction $\mathrm{M}_{1}$;

$$
\begin{gathered}
r_{1}=\sqrt{\frac{\kappa\left(d_{1}\right)\left(d_{2}+d_{3}+d_{4}\right)}{\left(d_{1}+d_{2}+d_{3}+d_{4}\right)}} \\
q_{1}=\frac{h_{1}}{r_{1}}
\end{gathered}
$$

For the knife edge obstruction $\mathrm{M}_{2}$

$$
\begin{gathered}
\mathrm{r}_{2}=\sqrt{\frac{\kappa\left(\mathrm{d}_{1}+\mathrm{d}_{2}\right)\left(\mathrm{d}_{3}+\mathrm{d}_{4}\right)}{\left(\mathrm{d}_{1}+\mathrm{d}_{2}+\mathrm{d}_{3}+\mathrm{d}_{4}\right)}} \\
\mathrm{q}_{2}=\frac{\mathrm{h}_{2}}{\mathrm{r}_{2}}
\end{gathered}
$$

For the knife edge obstruction $\mathrm{M}_{3}$

$$
\begin{gathered}
\mathrm{r}_{3}=\sqrt{\frac{\Lambda\left(\mathrm{d}_{1}+\mathrm{d}_{2}+\mathrm{d}_{3}\right)\left(\mathrm{d}_{4}\right)}{\left(\mathrm{d}_{1}+\mathrm{d}_{2}+\mathrm{d}_{3}+\mathrm{d}_{4}\right)}} \\
\mathrm{q}_{3}=\frac{\mathrm{h}_{3}}{\mathrm{r}_{3}}
\end{gathered}
$$

The dominant obstruction is the obstruction with the maximum value for $q_{i}$. After the dominant obstruction is identified, then two observation planes T'T and R'R are constructed as shown in the Figure 1. The diffraction loss is calculated for the dominant obstruction considering the height above the line between the "new" stations T' and R' [15]. After that the diffraction loss is calculated for the path between the original transmitter $\mathrm{T}$ and the main obstruction. Lastly, the diffraction loss is calculated for the path between the dominant obstruction and the original receiver $\mathrm{R}$. In this paper, the dominant obstruction is $\mathrm{M}_{2}$ and the LOS clearance $(\mathrm{H})$, distance from the transmitter $\left(D_{1}\right)$ and distance from the receiver $\left(D_{2}\right)$ are thus determined in respect of Giovaneli method applied to the three knife edge obstructions $\left(\mathrm{M}_{1}, \mathrm{M}_{2}\right.$ and $M_{3}$ ) in figure 1 . For the knife edge obstruction $M_{1}$ the following parameters are determined [15]

$$
\begin{gathered}
\mathrm{H}_{1}=\mathrm{h}_{1}-\mathrm{h}_{2}\left(\frac{\mathrm{d}_{1}}{\mathrm{~d}_{1}+\mathrm{d}_{2}}\right) \\
\mathrm{D}_{1(1)}=\mathrm{d}_{1} \\
\mathrm{D}_{2(1)}=\mathrm{d}_{2}
\end{gathered}
$$

The Fresnel-Kirchhoff diffraction parameter is given by [25, 26, 27]:

$$
\mathrm{V}_{1}=\mathrm{H}_{1} \sqrt{\left(\frac{2}{\lambda}\left(\frac{1}{\mathrm{D}_{1(1)}}+\frac{1}{\mathrm{D}_{2(1)}}\right)\right)}
$$

For the knife edge obstruction $\mathrm{M}_{2}$ the following parameters are determined [25]:

$$
\begin{gathered}
\mathrm{H}_{2}=\mathrm{h}_{2}-\mathrm{T}^{\prime}+\left(\mathrm{T}^{\prime}-\mathrm{R}^{\prime}\right)\left(\frac{\mathrm{d}_{1}+\mathrm{d}_{2}}{\mathrm{~d}_{1}+\mathrm{d}_{2}+\mathrm{d}_{3}+\mathrm{d}_{4}}\right) \\
\mathrm{D}_{1(2)}=\mathrm{d}_{1}+\mathrm{d}_{2} \\
\mathrm{D}_{2(2)}=\mathrm{d}_{3}+\mathrm{d}_{4}
\end{gathered}
$$

where $T^{\prime}$ and $R^{\prime}$ are given by:

$$
\begin{aligned}
& \mathrm{T}^{\prime}=\mathrm{h}_{1}-\left(\mathrm{h}_{2}-\mathrm{h}_{1}\right)\left(\frac{\mathrm{d}_{1}}{\mathrm{~d}_{2}}\right) \\
& \mathrm{R}^{\prime}=\mathrm{h}_{3}-\left(\mathrm{h}_{2}-\mathrm{h}_{3}\right)\left(\frac{\mathrm{d}_{4}}{\mathrm{~d}_{3}}\right)
\end{aligned}
$$

The Fresnel-Kirchhoff diffraction parameter for the knife edge obstruction $\mathrm{M}_{2}$ is given by:

$$
\mathrm{V}_{2}=\mathrm{H}_{2} \sqrt{\left(\frac{2}{\lambda}\left(\frac{1}{\mathrm{D}_{1(2)}}+\frac{1}{\mathrm{D}_{2(2)}}\right)\right)}
$$

For the knife edge obstruction $\mathrm{M}_{3}$ the following parameters are determined [25]:

$$
\begin{gathered}
\mathrm{H}_{3}=\mathrm{h}_{3}-\mathrm{h}_{2}\left(\frac{\mathrm{d}_{4}}{\mathrm{~d}_{3}+\mathrm{d}_{4}}\right) \\
\mathrm{D}_{1(3)}=\mathrm{d}_{3} \\
\mathrm{D}_{2(3)}=\mathrm{d}_{4}
\end{gathered}
$$

The Fresnel-Kirchhoff diffraction parameter for the knife edge obstruction $\mathrm{M}_{3}$ is given by:

$$
\mathrm{V}_{3}=\mathrm{H}_{3} \sqrt{\left(\frac{2}{\lambda}\left(\frac{1}{\mathrm{D}_{1(3)}}+\frac{1}{\mathrm{D}_{2(3)}}\right)\right)}
$$

The knife edge diffraction loss due to $\mathrm{v}_{i}$ is denoted as $\mathrm{A}_{i}$ and according to ITU-RP 526-13 [28] the knife-edge diffraction loss $A_{i}$ is defined as;

$$
A_{i}=6.9+20 \log \left(\left(\sqrt{\left(v_{i}-0.1\right)^{2}+1}\right)+v_{i}-0.1\right)
$$

The total diffraction loss due to the three knife edge 
obstructions $\left(M_{1}, M_{2}\right.$ and $\left.M_{3}\right)$ in figure 1 is A where;

$$
A=A_{1}+A_{2}+A_{3}
$$

According to ITU-RP 526-13 [28] diffraction parameter $\mathrm{v}$ will give rise to knife-edge diffraction loss $A$ defined as;

$$
A=6.9+20 \log \left(\left(\sqrt{(v-0.1)^{2}+1}\right)+V-0.1\right)
$$

Conversely, the diffraction parameter $\mathrm{v}$ can be computed from the knife-edge diffraction loss, $A$ as follows;

Let $\mathrm{P}$ be defined as

$$
10^{\left(\frac{A-6.9}{20}\right)}=P
$$

Also, let $\mathrm{U}$ be defined as

$$
\mathrm{U}=\mathrm{V}-0.1
$$

Then the ITU Rec 526-13 knife-edge diffraction loss gives;

$$
\sqrt{\left(U^{2}+1\right)}+\mathrm{U}=\mathrm{P}
$$

Hence,

$$
\begin{gathered}
\sqrt{\left(U^{2}+1\right)}=\mathrm{P}-\mathrm{U} \\
U^{2}+1=P^{2}-2(P)(U)+U^{2} \\
U^{2}+1=P^{2}-2(P)(U)+U^{2} \\
\mathrm{U}=\frac{P^{2}-1}{2(P)}
\end{gathered}
$$

Then

$$
\mathrm{V}=\left(\frac{\left(10^{\left.\left(\frac{A-6.9}{20}\right)\right)^{2}-1}\right.}{2\left(10\left(\frac{A-6.9}{20}\right)\right)}\right)+0.1
$$

So, the single knife edge equivalent of the dual knife edge is given by equation 17 . Let the single knife edge equivalent obstruction be located at a distance of $d_{t(x)}$ from the transmitter and at a distance of $d_{r(x)}$ from the receiver, then, the diffraction parameter, $\mathrm{V}$ is given as;

$$
\mathrm{V}=\mathrm{h} \sqrt{\frac{2\left(d_{t(x)}+d_{r(x)}\right)}{\lambda\left(d_{t(x)}\right)\left(d_{r(x)}\right)}}
$$

Then form

$$
\mathrm{h}=\frac{\mathrm{V}}{\left(\sqrt{\frac{2\left(d_{t(x)}+d_{r(x)}\right)}{\lambda\left(d_{t(x)}\right)\left(d_{r(x)}\right)}}\right)}
$$

The Percentage Clearance, $\mathrm{Pc}(\%)$ is given as ;

$$
\operatorname{Pc}(\%)=\left(\frac{\mathrm{h}}{\mathrm{r}_{x}}\right) 100 \%=\frac{(V) 100}{\sqrt{2}}
$$

The excess path length $\left(\Delta_{\text {path }}\right)$ is the difference between the direct path and the diffracted path it is given as;

$$
\Delta_{\text {path }}=\left(\frac{K}{4}\right) V^{2}
$$

The phase difference $(\phi)$ between the direct path and the diffracted path is given as;

$$
\Phi=\left(\frac{\pi}{2}\right) V^{2}
$$

Let $n_{\text {tip }}$ be the Fresnel zone in which the tip of the obstruction lies, then;

$$
n_{\text {tip }}=\left(\frac{1}{2}\right) V^{2}
$$

\begin{tabular}{|c|c|c|c|c|c|}
\hline $\mathbf{M}_{1}$ & & $\mathbf{M}_{2}$ & & $\mathbf{M}_{3}$ & \\
\hline $\begin{array}{l}\text { h1: Clearance height for obstruction } \\
\text { M1 }\end{array}$ & 23.64246 & $\begin{array}{l}\text { h2: Clearance height for obstruction } \\
\text { M2 }\end{array}$ & 45.19553 & $\begin{array}{l}\text { h3: Clearance height for obstruction } \\
\text { M3 }\end{array}$ & 17.48045 \\
\hline $\begin{array}{l}\text { r1: Radius of first Fresnel zone (m) } \\
\text { at the location of obstruction M1 }\end{array}$ & 43.13966 & $\begin{array}{l}\text { r2: Radius of first Fresnel zone }(\mathrm{m}) \\
\text { at the location of obstruction M2 }\end{array}$ & 66.51955 & $\begin{array}{l}\text { r3: Radius of first Fresnel zone }(\mathrm{m}) \\
\text { at the location of obstruction M3 }\end{array}$ & 33.3352 \\
\hline $\begin{array}{l}\text { q1: Ratio Of Clearance Height To } \\
\text { Fresnel Zone For Obstruction M1 }\end{array}$ & 0.548045 & $\begin{array}{l}\text { q2: Ratio Of Clearance Height To } \\
\text { Fresnel Zone For Obstruction M2 }\end{array}$ & 0.679432 & $\begin{array}{l}\text { q3: Ratio Of Clearance Height To } \\
\text { Fresnel Zone For Obstruction M3 }\end{array}$ & 0.524384 \\
\hline
\end{tabular}

\section{Results and Discussions}

The key input data for the three knife edge obstructions used in the study are shown in Table 1. Particularly, the heights of the obstructions above TR, (the transmitter-receiver line of sight) as well as the distance in kilometers between the obstructions. Table 2 shows the ratio of the LOS clearance height to the first Fresnel zone for the three obstructions. According to Table 2, among the three obtrusions considered in the study, obstruction M2 has the highest ratio of clearance height to the first Fresnel zone. Hence, obstruction M2 is the dominant obstruction.

Table 1. Data on height of obstruction above the transmitter-receiver line of sight and the distance between the obstructions.

\begin{tabular}{llll}
\hline \multicolumn{2}{l}{$\begin{array}{l}\text { Distance Between The } \\
\text { Obstructions }\end{array}$} & \multicolumn{2}{l}{$\begin{array}{l}\text { Height Of Obstruction Above TR, The } \\
\text { Transmitter-Receiver Line Of Sight }\end{array}$} \\
\hline $\mathrm{d} 1(\mathrm{~km})$ & 1.8 & $\mathrm{~h} 1(\mathrm{~m})$ & 23.64246 \\
$\mathrm{~d} 2(\mathrm{~km})$ & 2.25 & $\mathrm{~h} 2(\mathrm{~m})$ & 45.19553 \\
$\mathrm{~d} 3(\mathrm{~km})$ & 3.6 & $\mathrm{~h} 3(\mathrm{~m})$ & 17.48045 \\
$\mathrm{~d} 4(\mathrm{~km})$ & 1.3 & & \\
\hline
\end{tabular}

Table 2. The Ratio Of Clearance Height To Fresnel Zone For Obstructions $\boldsymbol{M}_{\mathbf{1}}, \boldsymbol{M}_{\mathbf{2}}$ and $\boldsymbol{M}_{\mathbf{3}}$ ).

Table 3 shows the total diffraction loss of $59.5095778 \mathrm{~dB}$ as computed by the Giovanelli method. The individual diffraction loss from obstructions M1, M2 and M3 are
$13.3856983 \mathrm{~dB}, 29.59291 \mathrm{~dB}$ and $16.5309693 \mathrm{~dB}$ respectively. Table 4 shows the single knife edge equivalent parameters for the three knife edge obstructions M1, M2 and M3. According 
to the results in Table 4, a single knife edge obstruction located at the middle of the link $(\mathrm{dt}=\mathrm{dr}=4475 \mathrm{~m})$ and with LOS clearance height of $1237.591 \mathrm{~m}$ will be give the same diffraction loss as the three knife edge obstructions M1, M2 and $\mathrm{M} 3$.

Table 3. The Effective Diffraction Of The Three Knife Edge Computed By The Giovanelli Method.

\begin{tabular}{|c|c|c|c|}
\hline & M1 & M2 & M3 \\
\hline & $\mathbf{j}=\mathbf{1}$ & $\mathbf{j}=\mathbf{2}$ & $\mathbf{j}=\mathbf{3}$ \\
\hline Distance of obstruction from the transmitter, D1(j) in meter & 1800 & 4050 & 3600 \\
\hline Distance of obstruction from the receiver, D2(j) in meter & 2250 & 4900 & 1300 \\
\hline LOS Clearance Height, H(j) in meter & 3.55555556 & 39.68176 & 5.48979592 \\
\hline Diffraction Parameter, V(j) & 0.9180405 & 6.880678 & 1.45039296 \\
\hline Diffraction Loss, $\mathrm{A}(\mathrm{j})$ in $\mathrm{dB}$ & 13.3856983 & 29.59291 & 16.5309693 \\
\hline Total Diffraction Loss, $\mathrm{A}$ in $\mathrm{dB}$ & & & 59.5095778 \\
\hline $\mathrm{T}^{\prime}$ & 6400 & $\mathrm{R}^{\prime}$ & 7472.22222 \\
\hline
\end{tabular}

Table 4. The Single Knife Edge Equivalent Of The Three Knife Edge Obstructions.

\begin{tabular}{|c|c|c|c|c|c|}
\hline Single Knife Edge Diffraction Loss & $\mathbf{G}(\mathrm{dB})$ & 59.50958 & Single Knife Edge Radius of First Fresnel Zone & Fr1 & 8.192985 \\
\hline Single Knife Edge Diffraction Parameter & $\mathrm{V}$ & 213.6239 & $\begin{array}{l}\text { Percentage Clearance Of The Single Knife Edge } \\
\text { Obstruction }\end{array}$ & $\mathrm{P}(\%)$ & 15105.49 \\
\hline $\begin{array}{l}\text { Single Knife Edge Obstruction Distance } \\
\text { From transmitter }\end{array}$ & $\mathrm{dt}(\mathrm{m})$ & 4475 & Excess path length & $\Delta_{\text {path }}(\mathrm{m})$ & 342.2638 \\
\hline $\begin{array}{l}\text { Single Knife Edge Obstruction Distance } \\
\text { From transmitter }\end{array}$ & $\operatorname{dr}(\mathrm{m})$ & 4475 & The phase difference & $\Phi$ (radians) & 71692.86 \\
\hline $\begin{array}{l}\text { LOS Clearance Height of the Single Knife } \\
\text { Edge Obstruction }\end{array}$ & $\mathrm{h}$ & 1237.591 & $\begin{array}{l}\text { The Fresnel zone where the tip of the knife edge } \\
\text { obstruction is located }\end{array}$ & ntip & 22817.59 \\
\hline
\end{tabular}

\section{Conclusions}

The computation of three knife edge diffraction loss by Giovanelli multiple knife edge diffraction loss method is presented for a $10 \mathrm{GHz} \mathrm{Ku}$-band microwave link. Also presented are the computation of a single knife edge obstruction that will replace the three knife edge obstructions by giving the same diffraction loss as the three obstructions. The results shows that the line of sight clearance height of the equivalent single knife edge obstruction are much more than the sum of the line of sight clearance height of the three obstructions. Similar result applies to the diffraction parameter of the equivalent single knife edge obstruction in relation to the dual obstruction. Essentially, dual or multiple knife edge obstructions has more impact than a very high single knife edge obstruction.

\section{References}

[1] Popoola, S. I., \& Oseni, O. F. (2014). Empirical Path Loss Models for GSM Network Deployment in Makurdi, Nigeria. International Refereed Journal of Engineering and Science (IRJES), 3(6), 85-94.

[2] Cheng, L., Tsai, H. M., Viriyasitavat, W., \& Boban, M. (2016, October). Comparison of radio frequency and visible light propagation channel for vehicular communications. In Proceedings of the First ACM International Workshop on Smart, Autonomous, and Connected Vehicular Systems and Services (pp. 66-67). ACM.

[3] Sun, S., MacCartney, G. R., Samimi, M. K., Nie, S., \& Rappaport, T. S. (2014, June). Millimeter wave multi-beam antenna combining for $5 \mathrm{G}$ cellular link improvement in New
York City. In 2014 IEEE International Conference on Communications (ICC) (pp. 5468-5473). IEEE.

[4] Bai, T., Alkhateeb, A., \& Heath, R. W. (2014). Coverage and capacity of millimeter-wave cellular networks. IEEE Communications Magazine, 52(9), 70-77.

[5] Shah, N. M., \& Allnutt, J. E. (2014). A short note on the variation of path loss in the atmosphere. Journal of Atmospheric and Solar-Terrestrial Physics, 110, 58-62.

[6] Sharma, K., \& Nanglia, P. (2016). Transmission and Optimization of a $3 \mathrm{G} / 4 \mathrm{G}$ Microwave Network at $14 \mathrm{GHz}$. International Journal of Engineering Science, 6086.

[7] Aremu, O. A., Taiwo, O. A., Makinde, O. S., \& Adeniji, J. A. (2016). Experimental Study of Variation of Path Loss with Respect to Heights at GSM Frequency Band.

[8] Hrovat, A., Kandus, G., \& Javornik, T. (2014). A survey of radio propagation modeling for tunnels. IEEE Communications Surveys \& Tutorials, 16(2), 658-669.

[9] Choudhary, N., \& Sharma, A. K. (2010). Performance Evaluation of LR-WPAN for different Path-Loss Models. International Journal of Computer Applications (0975-8887) Volume.

[10] McNeill, P. R. (2002). RADIO FREQUENCY PROPAGATION DIFFERENCES THROUGH VARIOUS TRANSMISSIVE MATERIALS Patrick L. Ryan, BSIE (Doctoral dissertation, UNIVERSITY OF NORTH TEXAS).

[11] Mulligan, J. (1997). A Performance Analysis of a CSMA Multihop Packet Radio Network (Doctoral dissertation, Virginia Polytechnic Institute and State University).

[12] Yamamoto, A., Ogawa, K., Horimatsu, T., Kato, A., \& Fujise, M. (2008). Path-loss prediction models for intervehicle communication at $60 \mathrm{GHz}$. IEEE Transactions on vehicular technology, 57(1), 65-78. 
[13] He, R., Molisch, A. F., Tufvesson, F., Zhong, Z., Ai, B., \& Zhang, T. (2014). Vehicle-to-vehicle propagation models with large vehicle obstructions. IEEE Transactions on Intelligent Transportation Systems, 15(5), 2237-2248.

[14] Cowan, B., \& Kapralos, B. (2015, July). Interactive rate acoustical occlusion/diffraction modeling for 2D virtual environments \& games. In Information, Intelligence, Systems and Applications (IISA), 2015 6th International Conference on (pp. 1-6). IEEE.

[15] Jude, O. O., Jimoh, A. J., \& Eunice, A. B. (2016). Software for Fresnel-Kirchoff Single Knife-Edge Diffraction Loss Model. Mathematical and Software Engineering, 2(2), 76-84.

[16] Jayaram, M. N., \& Venugopal, C. R. (2014). Modeling-Simulation of an Underground Wireless Communication Channel. In Proceedings of International Conference on Internet Computing and Information Communications (pp. 81-91). Springer India

[17] Femi-Jemilohun, O. J. (2016). Effects of Diffraction Propagation at $24 \mathrm{GHz}$ Spectrum Band. Transactions on Networks and Communications, 3(6), 59.

[18] Tyson, R. K. (2014). Fresnel and Fraunhofer diffraction and wave optics. In Principles and Applications of Fourier Optics. IOP Publishing, Bristol, UK.

[19] Pedrotti, L. S. (2008). Basic physical optics. Fundamentals of Photonics, 152-154.
[20] Bock, R. D. (2016). On the Conventionality of Simultaneity and the Huygens-Fresnel-Miller Model of Wave Propagation. arXiv preprint arXiv:1608.01544.

[21] Östlin, E. (2009). On Radio Wave Propagation Measurements and Modelling for Cellular Mobile Radio Networks.

[22] Baldassaro, P. M. (2001). RF and GIS: Field Strength Prediction for Frequencies between $900 \mathrm{MHz}$ and $28 \mathrm{GHz}$.

[23] Qing, L. (2005). GIS Aided Radio Wave Propagation Modeling and Analysis (Doctoral dissertation, Virginia Polytechnic Institute and State University).

[24] Barclay, L. W. (2003). Propagation of radiowaves (Vol. 502). Iet.

[25] Wibling, O. (1998). Terrain Analysis with Radio Link Calculations for a Map Presentation Program. Terrain, 98, 12-08.

[26] Giovanelli CL (1984) An analysis of simplified solutions for multiple knife-edge diffraction. IEEE Transactions on Antennas and Propagation vol AP-32, 3: 297-301

[27] Sizun, H., \& de Fornel, P. (2005). Radio wave propagation for telecommunication applications. Heidelberg: Springer.

[28] ITU-R P. 526-13, "Propagation by diffraction," Series of ITU-R Recommendations, Nov, 2013. 